auf 60 orer 70 Sdjritte an Die F̧üdje heran, Die algdann it Den Bnid binein flühtig wurden. Beder i. now mein Begleiter hatten bet biefem Brenzbegange Brewehre bei uns, jouft hätten wir

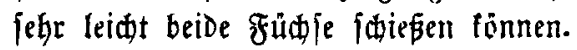

Şier haben alfo die frudjpe im zreien bei Tage geranzt, während auf 300 Edritte im anftopenden SBalde eit Futboau

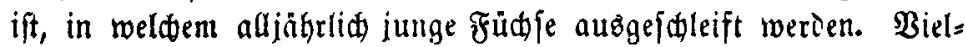

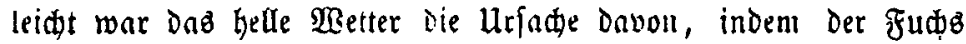
bet -hellem und trofenem $\mathfrak{B}$ etter nifts gerne in Baue ift.

Man hat fum Beifpiel Die (Erfahrung gemadst, Dos in redt

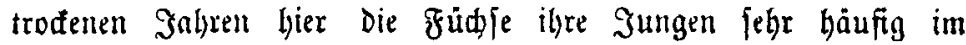

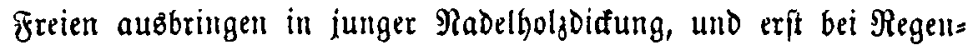
better in die Bảue jurúdfehren.

Oppertoeiler, 31. Mara 1869.

Ireiherr v. Sturmfèter.

\title{
fiterarifde Beridjte.
}

No. 12 .

Berfandlungen Des Şarzer Forftereing. Şernuagegeben bon Dem $\mathfrak{B}$ ereine. Jahrgang 1867. SBraunfwweig, Berlag Der Budfhandlung von \&. (5. (5. Mienar sen. 1868.

Der Şarger Foritterein, einer Der älteften und thätigften Forits = Dereine Deutialands, verjammelte fid am 2., 3. und 4. Septem= ber 1867 in Dem an Maturidjonbeiten fo reiden હdloffe Falfen=

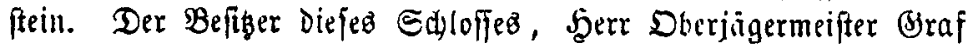
von Der \&ffefurg=Falfenftein, hatte Den Berein Dabin eingelnden uno ihn aufa freundictite rufgenommen.

Der $\mathfrak{B e r e i n g ̧ p r a ̈ f t i d e n t ~ e r o ̂ f f n e t e ~ a m ~ 2 . ~ E e p t e m b e r ~ M o r g e n z ~}$ 8 uhr die Berfammlung, madte auf Dad 24 jährige Beftehen, Die immer grögere Entfaltung und Das in näthten Zabre erfolgende 25jährige Jubiläum bes Bereinz aufmertfam und jaritt hierauf

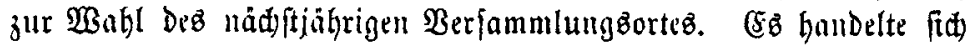
um Elaubal oder Rauterberg. Nath furjer Debatte wurde legteres pro 1868 angenommen und man ging nun alsbulb fur eigentliden Tage 